\title{
Correlation between optical properties, composition, and deposition parameters in pulsed laser deposited $\mathrm{LiNbO}_{3}$ films
}

\author{
C. N. Afonso, J. Gonzalo, and F. Vega \\ Instituto de Optica, CSIC, Serrano 121, 28006 Madrid, Spain \\ E. Dieguez \\ Departamento de Física de Materiales, Universidad Autonoma, 28049 Madrid, Spain \\ J. C. Cheang Wong, C. Ortega, J. Siejka, and G. Amsel \\ Groupe de Physique des Solides, Université de Paris 7 et 6, URA 17 du CNRS, 2 Place Jussieu, \\ 75251 Paris Cedex 05, France
}

(Received 7 March 1994; accepted for publication 20 January 1995)

\begin{abstract}
The correlation between the optical properties and composition of lithium niobate films is investigated in films deposited by laser ablation of single-crystal $\mathrm{LiNbO}_{3}$ and $\mathrm{Li}$ enriched $\mathrm{LiNbO}_{3}$ sintered targets under different oxygen pressures and laser fluences. The results show that the variation of the film refractive index is in many cases related to the deposition process itself, rather than to a variation of the film composition. The experimental conditions to produce stoichiometric films with optical properties similar to those of the bulk material are discussed. (C) 1995 American Institute of Physics.
\end{abstract}

Lithium niobate $\left(\mathrm{LiNbO}_{3}\right)$ is a well-known ferroelectric material with unique piezoelectric, electro-optic, and nonlinear optical properties. Due to the combination of these properties, lithium niobate films have a high potential for many applications in the photonic technology.

Among the various experimental techniques applied to produce good quality lithium niobate films, sputtering deposition is the most used. ${ }^{1-4}$ Laser ablation has been shown to be very suitable to form complex oxide films, ${ }^{5}$ and was recently applied to produce lithium niobate films. ${ }^{6-9}$ Amorphous films with refractive index similar to that of the bulk single-crystal material were obtained in this way, ${ }^{6}$ the optical properties of the film being strongly dependent on the oxygen pressure during deposition and on the laser fluence. Epitaxial films were grown on sapphire substrates held at 500$600{ }^{\circ} \mathrm{C}$ in oxygen ambient. ${ }^{7,9}$ Stoichiometric films were deposited on $\mathrm{Si}$ wafers by ablation in an argon-oxygen mixture. ${ }^{8}$ In most of the cases, the composition of the films was evaluated through x-ray studies or their optical properties. Rutherford backscattering spectrometry (RBS) with a 2 $\mathrm{MeV}{ }^{4} \mathrm{He}$ ion beam was used to determine the ratio of oxygen to niobium ${ }^{3}$ and it has been combined recently with nuclear reaction analysis (NRA) to determine, in addition, the lithium to niobium ratio through the proton induced ${ }^{7} \mathrm{Li}(p, \alpha){ }^{4} \mathrm{He}$ nuclear reaction. ${ }^{4}$

The aim of this letter is to correlate the film refractive index and composition with the deposition parameters. This allows us to determine the optimum conditions to produce films with optical properties and composition close to those of the bulk. The films are grown by laser ablation of $\mathrm{LiNbO}_{3}$ and $\mathrm{Li}$ enriched $\mathrm{LiNbO}_{3}$ targets both in vacuum and in an oxygen atmosphere. Moreover, we report a new method to determine the composition of $\mathrm{LiNbO}_{3}$ films based on the use of a deuteron beam to perform simultaneous RBS and NRA measurements. This method uses a single beam that, in contrast to the two beams used in Ref. 4, eliminates errors due to charge normalization and lateral film inhomogeneities and leads to a better precision.

The experimental setup for film deposition includes an ArF laser $(\lambda=193 \mathrm{~nm}, \tau=12 \mathrm{~ns})$ and has been described in detail elsewhere. ${ }^{6}$ The substrates are (100) Si wafers held at room temperature. A He-Ne laser beam $(\lambda=632.8 \mathrm{~nm})$ is used to record in real time the evolution of the reflectivity of the substrate as the film grows. This allows us to determine both the real $(n)$ and imaginary $(k)$ parts of the refractive index $(n+i k) .^{6}$ The film thickness is, typically, $150 \mathrm{~nm}$. The optical properties and composition of the films were investigated as a function of the oxygen pressure during the ablation process in the $10^{-5}-10^{-1}$ mbar range, the laser fluence in the $0.4-2.5 \mathrm{~J} / \mathrm{cm}^{2}$ range and the target composition. A single-crystal $\mathrm{LiNbO}_{3}$ target and four different hotpressed sintered targets from $\mathrm{Li}_{2} \mathrm{CO}_{3}$ and $\mathrm{Nb}_{2} \mathrm{O}_{5}$ powders are used. The latter are sintered at $300 \mathrm{kgf} / \mathrm{cm}^{2}$ and subsequently heated up to $1100{ }^{\circ} \mathrm{C}$, in a three-step annealing process. The $\mathrm{Li} / \mathrm{Nb}$ molar ratio of the single-crystal target is close to the congruent value (0.94) whereas that of the sintered targets is in the 1.0-2.5 range.

The simultaneous NRA and RBS measurements were carried out with a deuteron beam at $850 \mathrm{keV}$ from the 2.5 $\mathrm{MeV}$ Van de Graaff accelerator of the Paris group. Two surface barrier detectors were used, one for $\mathrm{RBS}$ at $165^{\circ}$ in order to determine $\mathrm{Nb}$ and another for NRA at $150^{\circ}$ to record simultaneously the protons from the ${ }^{16} \mathrm{O}(d, p){ }^{17} \mathrm{O}^{*}$ nuclear reaction and the much more energetic $\alpha_{0}$ particles from the ${ }^{6} \mathrm{Li}\left(d, \alpha_{0}\right){ }^{4} \mathrm{He}$ reaction. In these conditions, the corresponding peaks in the energy spectra are well separated and free of background contributions; here, the cross section of the ${ }^{16} \mathrm{O}(d, p){ }^{17} \mathrm{O}^{*}$ reaction is nearly constant ${ }^{10}$ whereas that of ${ }^{6} \mathrm{Li}\left(d, \alpha_{0}\right){ }^{4} \mathrm{He}$ varies slightly with the energy. ${ }^{11,12}$ For films thinner than $0.2 \mu \mathrm{m}$ as in our case, the variation of both cross sections is negligible and the number of counts $(N)$ for each element is then proportional to the amount of atoms 


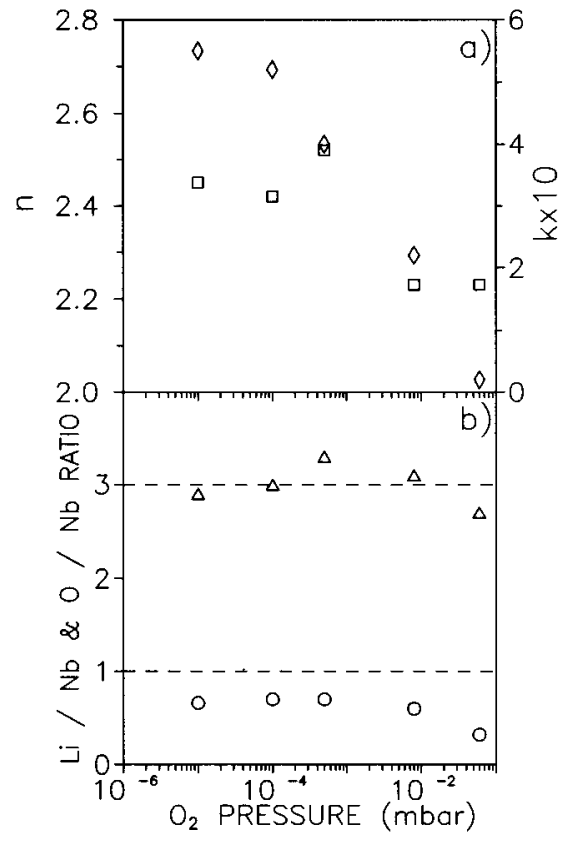

FIG. 1. (a) Real $(n, \square)$ and imaginary $(k, \diamond)$ parts of the refractive index and (b) $[\mathrm{Li}] /[\mathrm{Nb}](\bigcirc)$ and $[\mathrm{O}] /[\mathrm{Nb}](\triangle)$ ratios as a function of the oxygen pressure during the growth of the films. The results were obtained with a singlecrystal target at $1.6 \mathrm{~J} / \mathrm{cm}^{2}$ laser fluence.

contained in the films. The $\mathrm{N}_{\mathrm{O}} / \mathrm{N}_{\mathrm{Nb}}$ and $\mathrm{N}_{\mathrm{Li}} / \mathrm{N}_{\mathrm{Nb}}$ ratios are only affected by statistical errors that lead to a relative rootmean-square error in the present results of $0.5 \%$ and $4 \%$ for the $\mathrm{N}_{\mathrm{O}} / \mathrm{N}_{\mathrm{Nb}}$ and $\mathrm{N}_{\mathrm{Li}} / \mathrm{N}_{\mathrm{Nb}}$ ratios, respectively. These errors are the only ones to be taken into account in discussing the correlation between optical properties and film composition. In order to discuss the film stoichiometry, absolute errors have to be quoted. The absolute value of the $\mathrm{O}$ to $\mathrm{Nb}$ atomic ratio $([\mathrm{O}] /[\mathrm{Nb}])$ is calculated with a relative root-meansquare error of $\approx 1 \%$ by using a $\mathrm{Ta}_{2} \mathrm{O}_{5}$ film grown on a silicon wafer as a reference target. ${ }^{13}$ The absolute value of the $[\mathrm{Li}] /[\mathrm{Nb}]$ ratio is calculated within $\approx 20 \%$ by using a ${ }^{6} \mathrm{Li}$ and $\mathrm{Bi}$ ion implanted NRA and RBS reference target. The last error quoted here is mainly systematic and is dominated by the $20 \%$ uncertainty of the present ${ }^{6} \mathrm{Li}$ standard. The total Li content is determined taking into account the natural abundance of ${ }^{6} \mathrm{Li}, 7.42 \%$. In all figures the errors on the atomic ratios are of the order of or smaller than the size of the symbols except the $20 \%$ systematic error on the absolute scale of the $[\mathrm{Li}] /[\mathrm{Nb}]$ ratios that is not shown.

Figure 1 shows the dependence of $n, k$, and composition on the oxygen pressure during deposition. It is clearly seen in Fig. 1(a) that both $n$ and $k$ decrease as the oxygen pressure is increased. In contrast to that behavior, Fig. 1(b) shows that the composition of the films does not depend significantly on the oxygen pressure up to $10^{-2}$ mbar. Films grown at 6 $\times 10^{-2}$ mbar have $n=2.23 \pm 0.02$ that is very close to the ordinary refractive index of bulk single-crystal $\mathrm{LiNbO}_{3}$ (2.27, Ref. 14) and present a nearly negligible absorbance $(k<0.02)$. This oxygen pressure will hereafter be selected to analyze the influence of other deposition parameters. It is well known that the presence of defects and oxygen vacan-

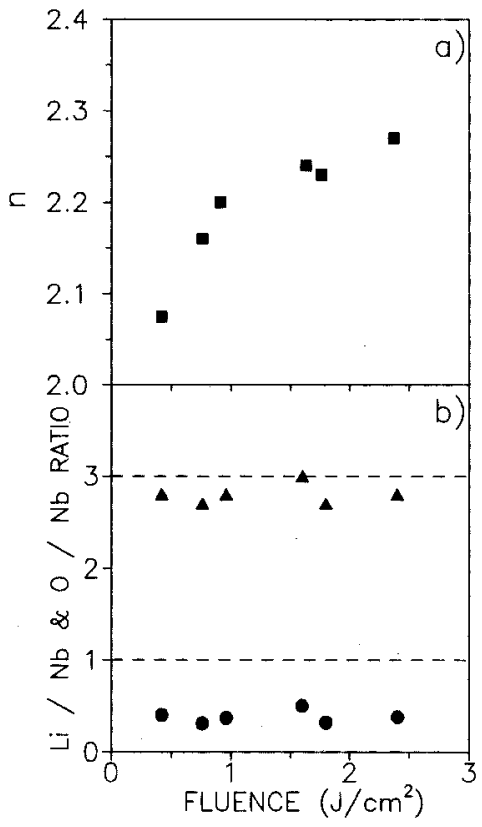

FIG. 2. (a) Real $(n, \boldsymbol{\square})$ part of the refractive index and (b) $[\mathrm{Li}] /[\mathrm{Nb}](\mathbf{\bullet})$ and $[\mathrm{O}] /[\mathrm{Nb}](\mathbf{\Lambda})$ ratios as a function of the laser fluence for films grown from a single-crystal target at an oxygen pressure of $6 \times 10^{-2}$ mbar.

cies in $\mathrm{LiNbO}_{3}$ crystals leads to strong absorption in the visible, ${ }^{15}$ heat treatments in an oxygen environment usually being required to obtain a transparent crystal. Since the results shown in Fig. 1 for pressures up to $10^{-2}$ mbar show no significant dependence of the film composition on the oxygen pressure, the strong change observed in $k$ may most probably be related to the formation of oxygen vacancies when films are grown in vacuum, the concentration of which is reduced as the oxygen pressure is increased.

Figure 2 shows that whereas $n$ increases significantly with the laser fluence, the film composition remains nearly constant within the experimental error. The optical diagnosis of the gas phase during ablation of $\mathrm{LiNbO}_{3}$ targets has shown that $\mathrm{Li}$ species follow a complex dynamics. ${ }^{6}$ Their velocity was found to increase significantly as the fluence increases, this dependence being similar to that of the refractive index shown in Fig. 2(a). Two explanations were tentatively given in Ref. 6 in order to explain the observed change in the refractive index; the arrival rate ratio of $\mathrm{Li}$ to $\mathrm{Nb}$ atoms at the substrate increases with fluence leading to films richer in lithium, or the ion bombardment during film growth enhances the film packing density and therefore increases the refractive index. ${ }^{16,17}$ Since Fig. 2(b) shows that there is no significant dependence of film composition on the laser fluence, the second explanation is more likely.

Figure 3 shows the dependence of $n$ and composition on the composition of the sintered targets for films grown both in vacuum $\left(10^{-5}\right.$ mbar) and in an oxygen pressure (6 $\times 10^{-2}$ mbar). It is clearly seen that films grown in vacuum always have lower oxygen and higher lithium contents than those grown in the same conditions under oxygen pressure. The refractive index variations of films grown in an oxygen pressure mirror those of the $[\mathrm{Li}] /[\mathrm{Nb}]$ and $[\mathrm{O}] /[\mathrm{Nb}]$ ratios, 


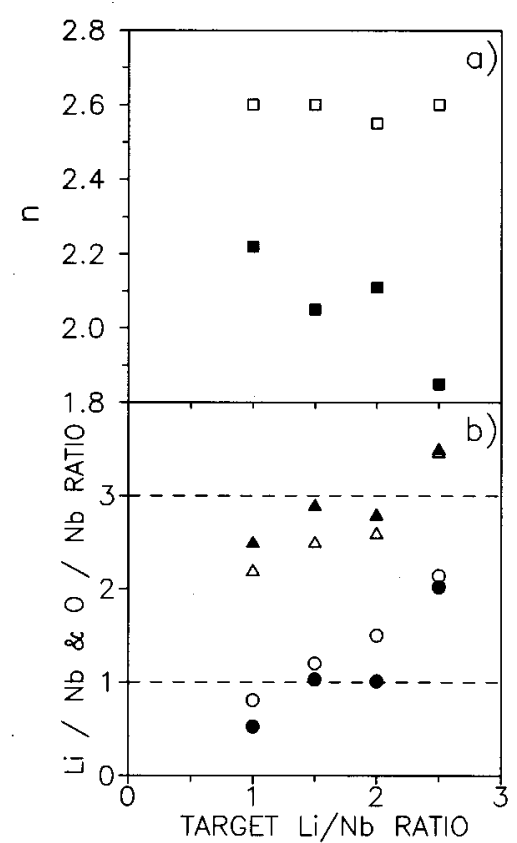

FIG. 3. (a) Real $(n, \square, \boldsymbol{\square})$ part of the refractive index and (b) $[\mathrm{Li}] /[\mathrm{Nb}]$ $(\mathrm{O}, \mathbf{O})$ and $[\mathrm{O}] /[\mathrm{Nb}](\triangle, \mathbf{\Lambda})$ ratios as a function of the $\mathrm{Li} / \mathrm{Nb}$ ratio of the sintered target. The results were obtained either in vacuum $(\square, \triangle, \bigcirc)$ or in an oxygen pressure of $6 \times 10^{-2} \mathrm{mbar}(\boldsymbol{\square}, \mathbf{\Lambda}, \boldsymbol{\Theta})$ at $1.6 \mathrm{~mJ} / \mathrm{cm}^{2}$ laser fluence.

showing lower $n$ values for higher lithium and oxygen contents, in contrast to what has been proposed earlier. ${ }^{1,2}$ It is also seen that the $[\mathrm{Li}] /[\mathrm{Nb}]$ and $[\mathrm{O}] /[\mathrm{Nb}]$ ratios increase as the target $\mathrm{Li} / \mathrm{Nb}$ molar ratio increases.

When using a reference target to calculate an absolute film composition, the present results show clearly that films grown from single-crystal targets are always deficient in $\mathrm{Li}$. Films grown in an oxygen pressure from $\mathrm{Li}$ enriched sintered targets show in contrast both $[\mathrm{O}] /[\mathrm{Nb}]$ and $[\mathrm{Li}] /[\mathrm{Nb}]$ ratios close to the stoichiometric values when using targets with a $\mathrm{Li} / \mathrm{Nb}$ molar fraction in the 1.5-2.0 range. The refractive index obtained under these conditions is nevertheless slightly lower than that of bulk $\mathrm{LiNbO}_{3}$. The presence of a high pressure foreign gas is known to influence the kinetics of the species in the gas phase at large distances from the target. A decrease of the species velocity is usually observed that influences the film properties. ${ }^{18,19}$ According to the discussion of the results plotted in Fig. 2, this change in the species velocity should lead to lower refractive index value. From the results in Figs. 2 and 3, it may be concluded that stoichiometric films with optical properties similar to those of the bulk material can be grown from a Li enriched target at a high laser fluence.

In summary, we have shown that laser ablation of $\mathrm{Li}$ enriched $\mathrm{LiNbO}_{3}$ targets with a $\mathrm{Li} / \mathrm{Nb}$ molar fraction of $1.5-$ 2.0 in an oxygen pressure of $6 \times 10^{-2}$ mbar lead to the formation of nearly stoichiometric films. Their optical properties depend on the laser fluence, the higher values $\left(2.5 \mathrm{~mJ} / \mathrm{cm}^{2}\right)$ leading to refractive index values close to that of the bulk material. The increase of the refractive index as the laser fluence increases is related to a change in the dynamics of the ablated species in the gas phase rather than to a composition change of the film.

The authors are grateful to O. Kaitasof and L. Chaumont, Université Paris-Sud, for providing the implanted ${ }^{6} \mathrm{Li}$ reference target. This work was partially supported by CICYT under TIC-93 program, Spain and by CNRS, GDR86, France. The CNRS-CSIC agreement is acknowledged for traveling finances.

${ }^{1}$ P. R. Meek, L. Holland, and P. D. Townsend, Thin Solid Films 141, 251 (1986).

${ }^{2}$ G. H. Hewig, K. Jain, F. O. Sequeda, R. Tom, and P. W. Wang, Thin Solid Films 88, 67 (1982).

${ }^{3}$ T. A. Rost, H. Lin, T. A. Rabson, R. C. Baumann, and D. L. Callahan, J. Appl. Phys. 72, 4336 (1992).

${ }^{4}$ C. H. J. Huang and T. A. Rabson, Opt. Lett. 18, 811 (1993).

${ }^{5}$ K. L. Saenger, Proc. Adv. Mater. 2, 1 (1993).

${ }^{6}$ C. N. Afonso, F. Vega, J. Gonzalo, and C. Zaldo, Appl. Surf. Sci. 69, 149 (1993).

${ }^{7}$ A. M. Marsh, S. D. Harkness, F. Qian, and R. K. Singh, Appl. Phys. Lett. 62, 952 (1993).

${ }^{8}$ S. B. Ogale, R. Nawathey-Dikshit, S. J. Dikshit, and S. M. Kanetkar, J. Appl. Phys. 71, 5718 (1992).

${ }^{9}$ Y. Shibata, K. Kaya, K. Akashi, M. Kanai, T. Kawai, and S. Kawai, Appl. Phys. Lett. 61, 1000 (1992).

${ }^{10}$ G. Amsel and D. Samuel, Anal. Chem. 39, 1686 (1967).

${ }^{11}$ D. Dieumegard, Faculté des Sciences d'Orsay, Université de Paris, France, 1971.

${ }^{12}$ B. Maurel, D. Dieumegard, and G. Amsel, in Ion Beam Handbook for Material Analysis, edited by J. W. Mayer and E. Rimini (Academic, New York, 1977), p. 129.

${ }^{13}$ G. Amsel, J. C. Cheang Wong, C. Ortega, S. Rigo, J. Siejka, F. Vega, B. Agius, and E. Cattan (unpublished).

${ }^{14}$ See for instance, Properties of Lithium Niobate, EMIS Datareview Series No. $5,1989$.

${ }^{15}$ A. García-Cabañes, E. Diéguez, J. M. Cabrera, and F. Agulló-López, J. Phys: Condens. Matter. 1, 6453 (1989); A. Garcí-Cabañes and J. M. Cabrera, J. Phys. Condens. Matter 5, 3367 (1993).

${ }^{16}$ J. K. Hirvonen, Mater. Sci. Rep. 6, 215 (1991).

${ }^{17}$ J. C. G. de Sande, C. N. Afonso, J. L. Escudero, R. Serna, F. Catalina, and E. Bernabeu, Appl. Opt. 31, 6133 (1992).

${ }^{18}$ J. Gonzalo, F. Vega, and C. N. Afonso, Thin Solid Films 241, 96 (1994).

${ }^{19}$ P. T. Murray and D. T. Peeler, Appl. Surf. Sci. 69, 225 (1993). 